\title{
P43
}

\section{The Development of Sub-seismic Fractures around a Fault - The Causes and the Implications for Fluid Flow}

\section{D.C. Tanner* (Leibniz Institute for Applied Geophysics) \& C.M. Krawczyk (Leibniz Institute for Applied Geophysics)}

\section{SUMMARY}

Three parameters control the development of secondary sub-seismic fractures: Material properties, the fault displacement and its morphology. We demonstrate how restoring seismic faults with three dimensional geometrical kinematic modelling can generate information about the intensity and orientation of the fractures around the fault. 


\section{Fault and Top Seals \\ Montpellier 2009}

Secondary fracturing around a fault is commonly seen in outcrops (as far as the outcrop exposure allows, Fig. 1), but unrecognizable in reflection seismics, where however the faults can be mapped in detail. Secondary fracturing is a function of three parameters; the material properties of the faulted rocks (mostly analysed with numerical methods), the amount of displacement on the fault, and a hitherto underrated factor - the morphology and roughness of the fault surface. On a larger scale, fault-surface related, secondary deformation has been recognized as fault-bend folds (e.g. Suppe \& Medwedeff 1990), but on a smaller, sub-seismic scale (less than 10 metres), this has rarely been investigated. Nevertheless, sub-seismic fracturing accounts for most of the near-fault permeability.

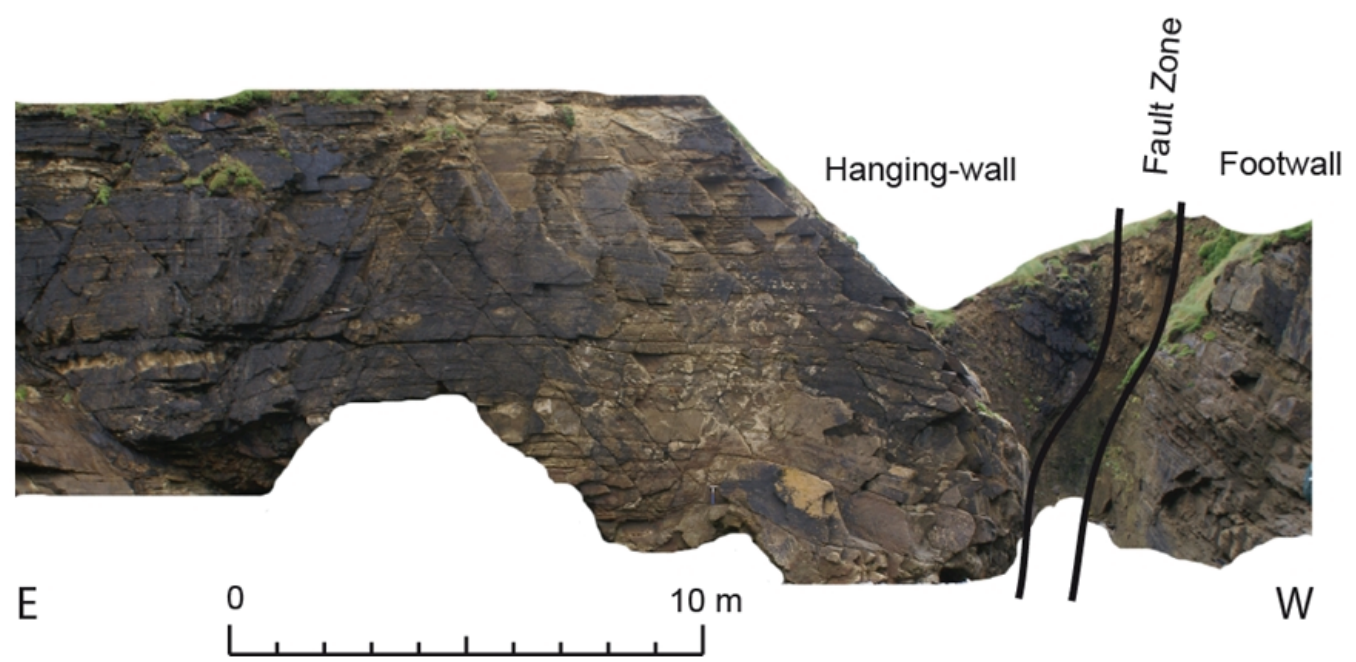

Figure 1 A fault exposed within thinly-bedded limestones and shales, western Ireland. The hanging-wall is extremely fractured by two main sets of sub-seismic fractures; antithetic and synthetic with respect to the fault. The fracture sets were generated at different times as the hanging-wall strata moved over the fault.

\section{The cause of sub-seismic deformation}

As strata move over a fault surface, they are deformed in the first place by the morphology of the fault. The deformation is directly proportional to the change in curvature of the fault surface, in the kinematic direction. In three-dimensions, changes in curvature, out of the kinematic plane, also cause local additional dilatational or compressional deformation. This applies to any point moving over the fault surface at any one time. After a certain amount of movement on the fault, the near fault strata will have undergone a polyphase deformation path (Fig. 1) and the total amount of deformation is proportional to the cumulative first derivative of the curvature of the fault surface.

\section{Predicting sub-seismic fracturing}

We use a geometrical modelling technique based on the software package 3DMove. This form of modelling takes in to account the three-dimensional morphology of the fault and faulted beds, and the displacement on the fault. By restoring fault displacement we can determine the strain tensor at any one point in the faulted volume, for any stage during the deformation history. Therefore, we can predict fracture orientation and density around the fault over time. Figure 2 shows such a prediction that could be verified and calibrated with borehole geophysics. The workflow is fully explained in Krawczyk et al. (2007).

\section{Implications for fluid flow}

Using the timing, orientation, and density of the fractures and using standard values for fracture width and length, we can determine near-fault fluid flow. Figure 2 suggests and Figure 1 shows that the fractures are sub-parallel to the strike of the fault, but dip at steep angles with respect to it. As long as only one fracture set is apparent, connectivity is poor, but 


\section{Fault and Top Seals \\ Montpellier 2009}

when a second set is introduced (Fig. 1), strong connectivity occurs and the fluid permeability rises accordingly.

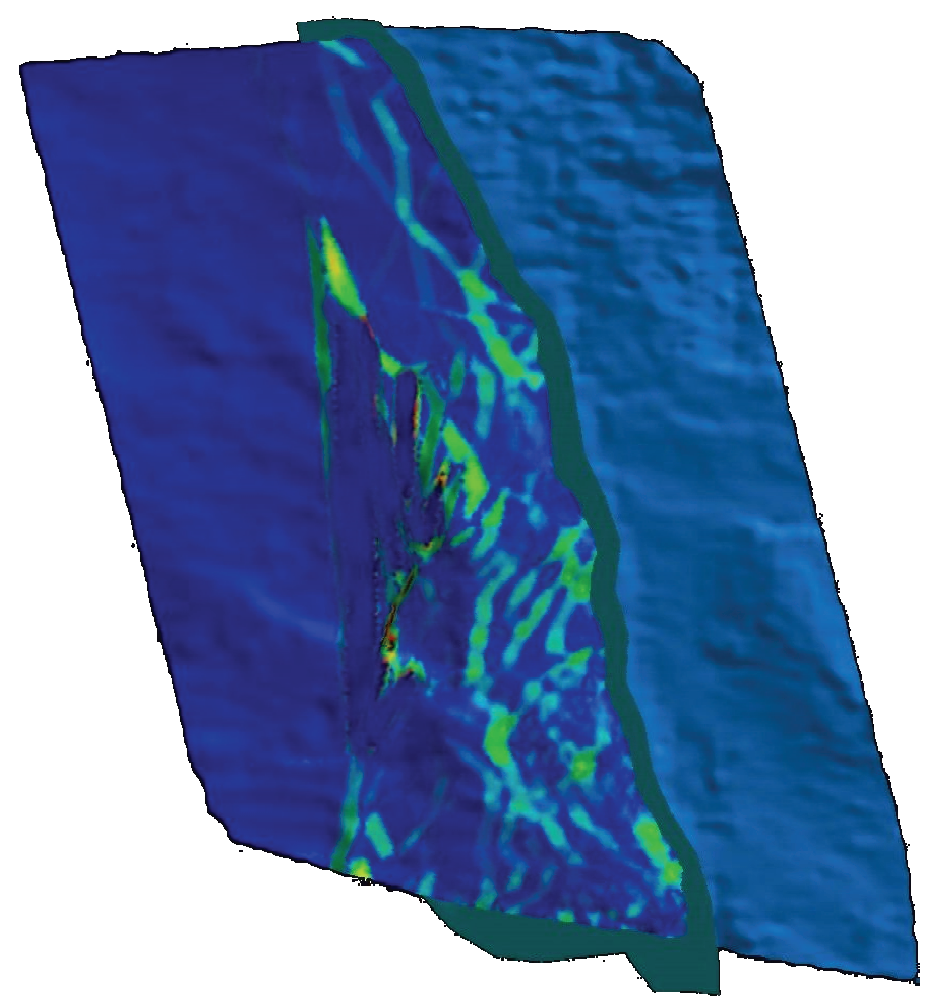

Figure 2 Map of the deformation intensity (value of $e_{1}$ (maximum strain) - red high, blue low) in the hanging-wall of a fault (dark blue surface), picked from three-dimensional seismics, after the fault displacement was restored. Note the heterogeneity of the deformation. Bands of deformation are directly attributable to fault curvature changes. After Lohr et al. (2008). Fault length is approximately $4 \mathrm{~km}$ along strike.

Consequently, the greater the displacement on the fault, the higher the probability of increased permeability, but the first order control is the fault morphology.

\section{Conclusions}

- Three parameters control secondary sub-seismic fracturing near to faults: The material properties of the faulted rock, the amount of fault displacement, and the fault morphology.

- Using kinematic geometrical modelling, the displacement on faults, picked from seismics, can be restored and the resulting strain tensor field used to determine fracture density and orientation.

- Analysis of the fracturing can determine the possible fluid flow over time.

\section{References cited}

Lohr, T., Krawczyk, C.M., Tanner, D.C., Samiee, R., Endres, H., Thierer, P.O., Oncken, O., Trappe, H., Bachmann, R. and Kukla, P.A. [2008] Prediction of sub-seismic faults and fractures - integration of 3D seismic data, 3D retrodeformation, and well data on an example of deformation around an inverted fault. AAPG Bulletin 92 (4), 473-485.

Krawczyk, C.M., Tanner, D.C., Endres, H., Samiee, R., Oncken, O., Trappe, H., Bachmann, R. and Kukla, P.A. [2007] 3D kinematic modelling - a workflow for identification of small-scale faults and fractures in 3D seismics. EAGE conference, London, UK, Extended Abstracts.

Suppe, J. and Medwedeff, D.A. [1990] Geometry and kinematics of fault-propagation folding. Eclogae Geologicae Helvatiae 83, 409-454. 